\title{
Combining complex systems analyses with process observations to understand stream dissolved organic carbon across scales
}

Julia Perdrial ${ }^{1}$, ThOMAs AdLeR ${ }^{2}$, CAITLIN Bristol ${ }^{3}$ KRISTEN UNDERWOOD ${ }^{4}$, DONNA RIZZO ${ }^{5}$, HANG WEN $^{6}$, $\mathrm{LI} \mathrm{LI}^{7}$, ADRIAN HARPOLD ${ }^{8}$, GARY STERLE ${ }^{9}$, JOHN HANLEY $^{10}$

${ }^{1}$ Department of Geology, University of Vermont (UVM), julia.perdrial@uvm.edu, ${ }^{2}$ Department of Geology, UVM, tadler@uvm.edu, ${ }^{3}$ Department of Geology, UVM, cbristol@uvm.edu, ${ }^{4}$ Department of Civil and Environmental Engineering (CEE), UVM, Kristen.Underwood@uvm.edu, ${ }^{5} \mathrm{CEE}$ UVM, drizzo@uvm.edu, ${ }^{6} \mathrm{CEE}$, Pennsylvania State University (PSU), lili@engr.psu.edu, ${ }^{7} \mathrm{CEE}$ PSU, hangwncloud@gmail.com, ${ }^{8}$ Department of Natural Resources and Environmental Science (NRES), University of Nevada, Reno (UNR), aharpold@cabnr.unr.edu, ${ }^{9}$ NRES UNR, gsterle@nevada.unr.edu, ${ }^{10}$ CEE UVM, john.hanley@uvm.edu

We present an example of using complex systems tools in combination with experiments can help investigate trends in dissolved organic carbon (DOC) concentrations and fluxes across scale from continental to the particle scale. For the statistical analyses, we used existing data from "catchment attributes and meteorology for large-sample studies" (CAMELS) and amended it with stream water chemistry and atmospheric deposition data for several hundreds of catchments. We then applied a novel evolutionary algorithm to identify key catchment attributes as drivers for DOC dynamics. Out of 50 catchment attributes, our analyses identified soil depth as the key control of DOC concentrations in streams across the US.

To investigate DOC response at the regional scale subjected to the same external driver (i.e. recovery from acidification), we investigated trends in stream DOC fluxes over the past decades for the eastern part of the US separately. Our flow adjusted Seasonal Kendall analyses indicated that, despite the common recovery from acidification driver, stream water response varied greatly. Experiments simulation acidification and recovery on soils of representative catchments showed that mineral content in soil aggregates controls DOC leaching from soils at this scale. These results indicate that, while soil thickness is an overarching driver, at the catchment scale additional drivers need to be considered to fully understand (and ultimately predict) DOC dynamics. 